\title{
Risk factors for poor tuberculosis treatment outcome in Finland: a cohort study
}

\author{
Tuula Vasankari*1,2, Pekka Holmström¹, Jukka Ollgren¹, Kari Liippo², \\ Maarit Kokki ${ }^{1}$ and Petri Ruutu ${ }^{1}$
}

\begin{abstract}
Address: ${ }^{1}$ Department of Infectious Disease Epidemiology, National Public Health Institute, Mannerheimintie 166, 00300 Helsinki, Finland and ${ }^{2}$ Department of Respiratory Medicine, Turku University Hospital, Paimio Hospital, Alvar Aallon tie 275, 21540 Preitilä, Finland

Email: Tuula Vasankari* - tuula.vasankari@utu.fi; Pekka Holmström - Pekka.Holmstrom@welho.com; Jukka Ollgren - jukka.ollgren@ktl.fi; Kari Liippo - Kari.Liippo@tyks.fi; Maarit Kokki - Maarit.KOKKI@ec.europa.eu; Petri Ruutu - petri.ruutu@ktl.fi

* Corresponding author
\end{abstract}

Published: 14 October 2007

BMC Public Health 2007, 7:291 doi:10.1 186/147|-2458-7-291

This article is available from: http://www.biomedcentral.com/I47I-2458/7/29।

(c) 2007 Vasankari et al.; licensee BioMed Central Ltd.

This is an Open Access article distributed under the terms of the Creative Commons Attribution License (http://creativecommons.org/licenses/by/2.0), which permits unrestricted use, distribution, and reproduction in any medium, provided the original work is properly cited.
Received: 18 December 2006

Accepted: 14 October 2007

\begin{abstract}
Background: We investigated the patient- and treatment-system dependent factors affecting treatment outcome in a two-year cohort of all treated culture-verified pulmonary tuberculosis (TB) cases to establish a basis for improving outcomes.

Methods: Medical records of all cases in 1995 - 1996 were abstracted to assess outcome of treatment. Outcome was divided into three groups: favourable, death and other unfavourable. Predictors of unfavourable outcome were assessed in univariate and multivariate analysis.

Results: Among 629 cases a favourable outcome was achieved in 44I (70.1\%), 17.2\% (108) died and other unfavourable outcome took place in $12.7 \%(80)$. Significant independent risk factors for death were male sex, high age, non-HIV -related immunosuppression and any other than a pulmonary specialty being responsible for stopping treatment. History of previous tuberculosis was inversely associated with the risk of death. For other unfavourable treatment outcomes, significant risk factors were pause(s) in treatment, treatment with INH+RIF+EMB/SM, and internal medicine specialty being responsible at the end of the treatment.
\end{abstract}

Conclusion: We observed a significant association with unfavourable outcome for the specialty responsible for treatment being other than pulmonary, but not for the volume of cases, which has implications for system arrangements. Poor outcomes associated with immunosuppression and advanced age, with frequent comorbidity, stress a low threshold of suspicion, availability of rapid diagnostics, and early empiric treatment as probable approaches in attempting to improve treatment outcomes in countries with very low incidence of TB.

\section{Background}

Early diagnosis of tuberculosis and effective treatment are the key elements in reduction of transmission of infection and finally achieving elimination of TB [1]. World Health Organization (WHO) has set the international target value for a favourable treatment outcome at 85\% [2]. Treatment outcome monitoring is a core part of surveillance necessary to succeed in tuberculosis elimination [3]. The WHO has published a recommendations for assessing 
the outcome of tuberculosis treatment in 1990's [4], revised recently $[5,6]$.

In many industrialized countries with good treatment facilities and a secured supply of drugs free of charge for patients, treatment results have not reached the targets set by WHO [7-18]. The main reason for this is the high rate of death as an unfavourable outcome, frequently with much comorbidity from other diseases. Incomplete treatment carries a risk of development of resistance, increased disease transmission, and increased morbidity and mortality [19]. In our earlier report from Finland, a favourable outcome was reached in only $65 \%$, death being the outcome in as much as $19 \%$, and defaulting, transferring out or physician's decision to stop treatment early being reasons for other unfavourable outcomes in $12 \%$ of the cases [20].

The specific reasons for unsuccessful outcomes are important in order to improve treatment systems. In a recent outcome analysis from Norway, where the large majority of TB cases are in immigrants, only high age and isoniazid (INH) resistance were significant risk factors for non-successful outcome [21]. In earlier studies, high age, alcoholism, HIV-infection, male sex and immigration have been associated with unfavourable outcomes $[7,12,22]$.

In low incidence countries, many of the clinical units treating tuberculosis patients have small and decreasing numbers of patients. This necessitates an assessment of the need to concentrate patients in fewer units to retain the level of experience sufficient for successful outcomes. There is varying evidence from assessments made in other areas of complex treatments, such as leukaemia, AIDS, demanding surgery and myocardial infarction, that the volume of treatments has an effect on the outcome $[23,24]$. It is possible that treatment organisation and implementation in bigger hospitals are more effective and up to date [25]. However, there is little data available on whether the volume of tuberculosis patients treated would associate with favourable outcomes.

We assessed the patient and treatment system dependent factors affecting treatment outcome in a national, population-based two-year cohort of all culture-verified pulmonary tuberculosis cases in Finland, with a TB incidence of 12,5 per 100000 per year during the study period, to establish a basis for improving the proportion of favourable outcomes.

\section{Methods}

Study cohort, case definitions and data collection

The method of identifying all culture-confirmed tuberculosis cases in Finland, with the first positive culture sample date between January $1^{\text {st }}, 1995$, to December $31^{\text {st }}$,
1996 ( $\mathrm{N}=1059)$, present in either the National Infectious Disease Register (NIDR) or through a separate query to all microbiological laboratories has been described elsewhere [26].

A case of tuberculosis was defined for the study as pulmonary using the case definition of NIDR, i.e. as a culture finding for M. tuberculosis in sputum or bronchoalveolar lavage (BAL), or as a culture finding for M. tuberculosis from another sample type in a case with sputum smear positive for acid fast bacilli. With this definition, 737 (70 $\%$ of the whole cohort) cases with pulmonary tuberculosis were identified. Species identification for Mycobacterium tuberculosis was carried out in every case. There were altogether 660 isolations of mycobacteria other than $\mathrm{M}$. tuberculosis during the study period. Only culture positive cases were taken into the study in order to be able to study only the fully confirmed cases.

Out of the 737 pulmonary tuberculosis cases, complete medical records were available from 711 (96\%). Among these 711 cases, twenty-two (3.1\%) had previously been treated for tuberculosis after the year 1970, and were excluded from the outcome analysis as re-treatment cases. Of the 689 cases, 33 were still on treatment at 12 months, and were also excluded from the analysis. Of the remaining 656 cases, 27 were not treated, among them 19 $(70.4 \%)$ were men and $8(29.6 \%)$ women. Of this group, with a median age of 82.0 years, 24 died before treatment and 3 were left untreated. Those without treatment were excluded from the main analysis of 629 actually treated cases (Figure 1).

\section{Definitions of treatment}

Tuberculosis treatment was initiated in and supervised by the pulmonary departments of public hospitals in the great majority of cases. Chemotherapy actually given to each patient, according to record review, was grouped into six categories (Table 1). Definitions for the grouping were based on the national recommendations in Finland following the recommendations by WHO, ATS and BTS [2732]. We have previously described the treatment grouping in detail [20]. Duration of treatment was assessed only for standard treatment groups (A - D). In the combination of isoniazid, rifampicin and pyrazinamide (HRZ) with or without an extra drug, the recommended duration of treatment was defined as $167-213$ days. For the combination isoniazid, rifampicin and ethambutol (HRE) or isoniazid, rifampicin and streptomycin (HRS) \pm extra drug, the recommended duration of treatment was defined as 243 - 304 days. Pauses of chemotherapy were recorded only when lasting at least one week, and calculated only for standard treatments. 


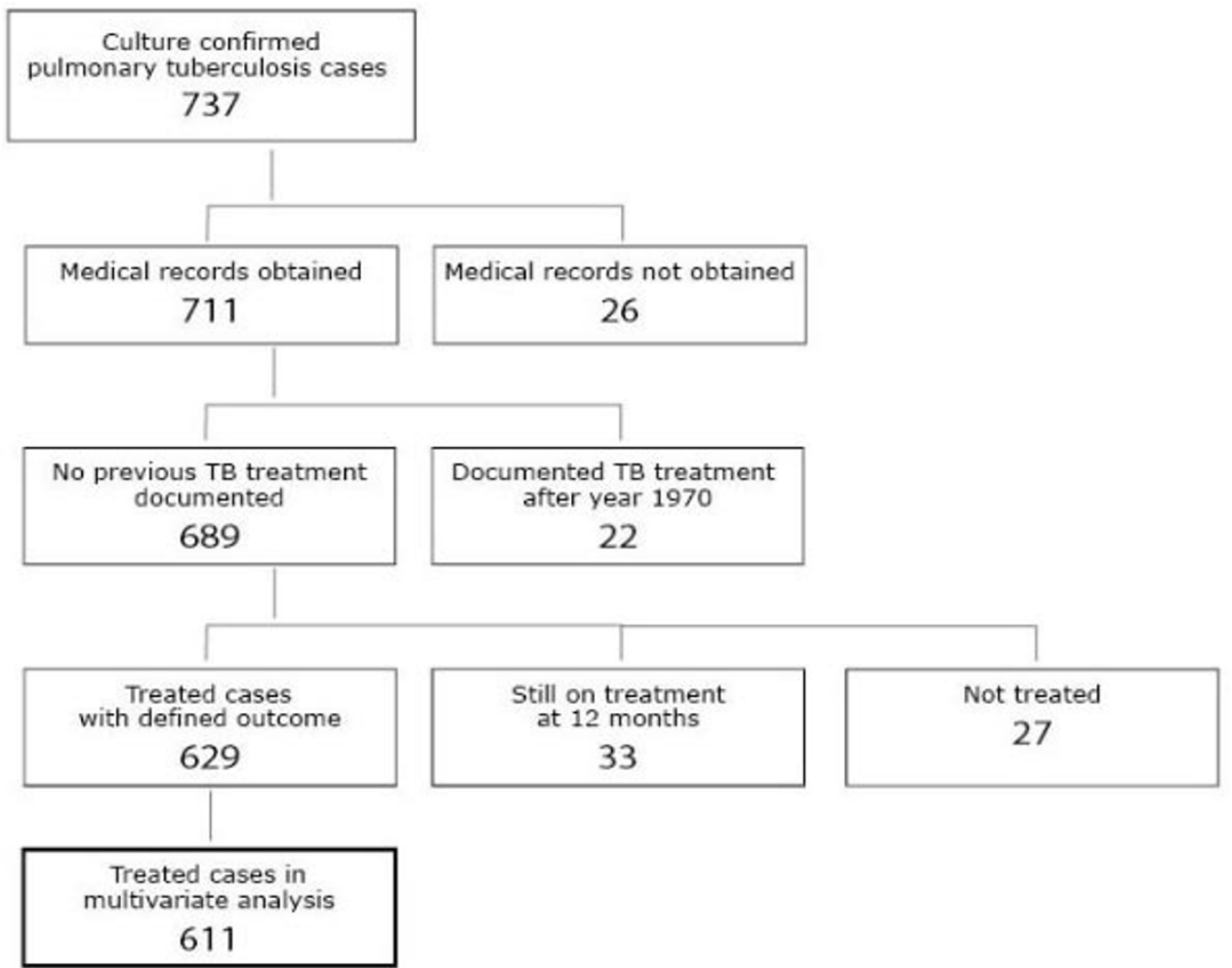

Figure I

Composition of the national study cohort of culture-confirmed pulmonary tuberculosis cases treated at least 24 hours included in analysis.

Table I: Definitions used in describing the treatment given to the cases in a national cohort of patients with pulmonary tuberculosis

\begin{tabular}{|c|c|c|c|c|}
\hline Treatment group & $\begin{array}{l}\text { Drugs used in intensive } \\
\text { phase }\end{array}$ & $\begin{array}{l}\text { Duration of } \\
\text { intensive phase [days] }\end{array}$ & $\begin{array}{l}\text { Drugs used in } \\
\text { continuation phase }\end{array}$ & $\begin{array}{l}\text { Total duration of } \\
\text { treatment [months] }\end{array}$ \\
\hline Standard treatment $A$ & $\begin{array}{l}\text { isoniazid + rifampicin + } \\
\text { pyrazinamide }\end{array}$ & At least 54 & isoniazid + rifampicin & At least $5 \mathrm{I} / 2$ \\
\hline Standard treatment B & $\begin{array}{l}\text { isoniazid + rifampicin }+ \\
\text { ethambutol or streptomycin }\end{array}$ & At least 54 & isoniazid + rifampicin & At least 8 \\
\hline $\begin{array}{l}\text { Standard treatment } \\
\text { with short intensive } \\
\text { phase C }\end{array}$ & $\begin{array}{l}\text { isoniazid }+ \text { rifampicin }+ \\
\text { pyrazinamide or ethambutol or } \\
\text { streptomycin }\end{array}$ & Less than 54 & isoniazid + rifampicin & $\begin{array}{l}\text { At least } 5 \mathrm{I} / 2 \text { for } A \mathrm{At} \\
\text { least } 8 \text { for } B\end{array}$ \\
\hline Standard treatment $D$ & $\begin{array}{l}\geq 4 \text { tuberculosis drugs, including } \\
\text { the drugs in Standard treatment } \\
A \text { or } B\end{array}$ & At least 54 & $\begin{array}{l}\text { isoniazid }+ \text { rifampicin } \pm \text { any } \\
\text { other anti-tuberculosis drug(s) }\end{array}$ & $\begin{array}{l}\text { At least } 5 \mathrm{I} / 2 \text { for } A \mathrm{At} \\
\text { least } 8 \text { for } B\end{array}$ \\
\hline $\begin{array}{l}\text { Other combination of } \\
\text { tuberculosis drugs }\end{array}$ & $\begin{array}{l}\text { Non-standard combinations of } \\
\text { tuberculosis drugs, excluding } \\
\text { the combinations above }\end{array}$ & $\mathrm{NA}^{2}$ & $\begin{array}{l}\text { Any combination of } \\
\text { antituberculosis drugs }\end{array}$ & NA \\
\hline Ineffective treatment & $\begin{array}{l}\text { One antituberculosis drug used } \\
\text { alone or in combination with a } \\
\text { drug with limited } \\
\text { antituberculosis activityl }\end{array}$ & NA & NA & NA \\
\hline
\end{tabular}

\footnotetext{
'E.g. fluoroquinolones $2 \mathrm{NA}=$ not applicable
} 


\section{Definitions of outcome}

The categories of WHO/EuroTB recommendation [6] for outcome monitoring are cure, treatment completed, failure, death, treatment interrupted (default), transfer out, and on treatment at 12 months. The duration of the follow up period is defined as 12 months from the beginning of the treatment or the date of diagnosis, and the first outcome registered as final.

The WHO/EuroTB category 'treatment interrupted' includes all treatment courses which remained shorter than defined above, whether caused by a patient or by a treating physician. For analysing these two separately, we divided 'treatment interrupted' into 'physician's decision to stop early' and 'default' for interruptions due to patient only [20]. The outcome was recorded as 'death', if the case died before starting the treatment (not included in the current analysis), during the treatment, or the date of death was within 14 days after cessation of the anti-TB drugs.

The outcome was categorized as favourable in cases of cure and treatment completed, and as unfavourable in cases of failure, death, default, physician's decision to stop early and transfer out.

\section{Definitions of origin, social and medical risk factors}

A case was defined as immigrant if the country of birth was not Finland or, in the absence of country of birth, the nationality was other than Finnish. Immunosuppressive treatment was defined as corticosteroid treatment $(>40$ mg per day of any duration, or any daily dose with duration exceeding one month), cytotoxic or cyclosporine treatment, or radiation therapy during the preceding year. For inclusion in the group of social risk factors, a case should have a history of alcohol abuse, unemployment, imprisonment or homelessness recorded in patient records. Diabetes was defined as juvenile or adult onset disease on medication.

\section{Definitions of characteristics of treatment system}

Specialty responsible for treatment was that of the unit treating patient as an inpatient or outpatient. Change of specialty included any change from one speciality to another during treatment.

\section{Ethical review}

The ethics approval for this study was acquired from the National Research and Development Centre for Welfare and Health.

\section{Statistical methods}

We used multinomial logistic regression model to assess the relationships between all potential predictors, listed in the univariate analysis, and a 3-class outcome variable, in which reference class was favourable outcome. To the final model significant predictors were selected using forward stepwise methods. Any variable whose univariable test had a p-value $<0.20$ was included in the multivariable analysis. P-values under 5\% were considered as significant. For univariate results Chi squared test and Fisher's exact test were used.

\section{Results}

In the study cohort of 629 cases, 386 (61.4\%) were men and $243(38.6 \%)$ women. The mean age was 62.9 years, the median 67.2 . The proportion of cases aged $\geq 65$ years was $339(53.9 \%)$. The proportion of immigrants was $4.1 \%$ (26 cases), mainly from developing countries (Table $2)$. Only two patients in the cohort had HIV-coinfection. There were no prisoners.

A favourable outcome was achieved in 441 (70.1\%) of the cases, consisting of those cured 199 (31.6\%) and treatment completed $242(38.5 \%)$. There were no treatment failures in the cohort. The proportion of cases defaulting or transferring out was $32(5.1 \%)$. For 48 (7.6\%) cases, treatment was stopped prematurely by physician. Death was the outcome in $17.2 \%(108 / 629)$ cases.

In univariate analysis, patient-related risk factors which were significantly associated $(\mathrm{p}<0.05)$ with death, were age $\geq 65$ years, social risk factor, immunosuppression and malignancy (Table 2). Treatment system -related risk factors which were significantly associated with death were the specialty of the treating unit (internal medicine, general medicine in primary care), less than five treated cases per year per unit, ineffective treatment combination and change in the treatment group (Table 3 ). The only statistically significant patient-related personal risk factor association for other unfavourable outcome (i.e. transfer out, default or physician's decision to stop early), was immigration (Table 2). Treatment system -related significant risk factors for other unfavourable outcome were internal medicine as the last treating specialty, standard treatment $\mathrm{B}$ and pause(s) during treatment (Table 3). For all unfavourable outcomes together, i.e. death and other unfavourable outcome combined, significant predictors in univariate analysis were gender, immunosuppression, malignancy, earlier TB, any other than a pulmonary unit being responsible at the end of the treatment, treatment group, pause(s) during treatment, less than five treated cases per year per unit and any change of specialty responsible for treatment.

Significant independent risk factors for death in multinomial logistic regression model were male sex, high age, immunosuppression and any other than a pulmonary specialty being responsible at the end of the treatment. History of previous tuberculosis was inversely associated 
Table 2: Univariate analysis of the association of patient - related characteristics with an unfavourable outcome in 629 cases treated for at least 24 hours

\begin{tabular}{|c|c|c|c|c|c|c|c|c|}
\hline \multirow[t]{2}{*}{ Variable } & & \multirow{2}{*}{$\begin{array}{c}\text { Total } \\
\mathrm{N}\end{array}$} & \multicolumn{3}{|c|}{ Death } & \multicolumn{3}{|c|}{ Other unfavourable } \\
\hline & & & $\mathrm{N}$ & OR $(95 \% \mathrm{Cl})$ & $P$ & $N$ & OR $(95 \% \mathrm{Cl})$ & $P$ \\
\hline \multirow[t]{2}{*}{ Sex } & female & 243 & 35 & 1 & & 30 & 1 & \\
\hline & male & 386 & 73 & $1.4 \mathrm{I}(0.90-2.204)$ & 0.15 & 50 & $1.13(0.69-1.84)$ & 0.71 \\
\hline \multirow[t]{3}{*}{ Age group } & $0-44$ & 118 & 6 & $\mathrm{I}$ & & 20 & $\mathrm{I}$ & \\
\hline & $45-64$ & 172 & 18 & $2.12(0.8 \mathrm{I}-5.56)$ & 0.12 & 24 & $0.85(0.44-1.63)$ & 0.62 \\
\hline & $65-$ & 339 & 84 & $5.89(2.48-13.94)$ & $<0.001$ & 36 & $0.75(0.42-1.38)$ & 0.36 \\
\hline \multirow[t]{2}{*}{ TB history } & no & 570 & 101 & 1 & & 76 & 1 & \\
\hline & yes & 59 & 7 & $0.57(0.25-1.29)$ & 0.21 & 4 & $0.43(0.15-1.23)$ & 0.15 \\
\hline \multirow[t]{2}{*}{ Social risk factor ${ }^{1}$} & no & 330 & 76 & I & & 33 & 1 & \\
\hline & yes & 295 & 32 & $0.43(0.27-0.68)$ & $<0.001$ & 46 & $1.42(0.87-2.30)$ & 0.18 \\
\hline \multirow[t]{2}{*}{ Birthplace or nationality } & Finland & 603 & 107 & $\mathrm{I}$ & & 72 & $\mathrm{I}$ & \\
\hline & abroad & 26 & 1 & $0.23(0.031-1.77)$ & 0.22 & 8 & $2.77(1.15-6.66)$ & 0.040 \\
\hline \multirow[t]{2}{*}{ Immunosuppression } & no & 548 & 78 & $\mathrm{I}$ & & 76 & 1 & \\
\hline & yes & 81 & 30 & $3.22(1.92-5.42)$ & $<0.001$ & 4 & $0.44(0.15-11.3)$ & 0.15 \\
\hline \multirow[t]{2}{*}{ Malignancy ${ }^{2}$} & no & 613 & 102 & I & & 77 & 1 & \\
\hline & yes & 15 & 6 & $4.26(1.35-13.46)$ & 0.017 & 3 & $2.82(0.69-11.5)$ & 0.15 \\
\hline \multirow[t]{2}{*}{ Diabetes } & no & 537 & 86 & 1 & & 73 & 1 & \\
\hline & yes & 92 & 22 & $1.54(0.86-2.63)$ & 0.14 & 7 & $0.58(0.25-1.3 \mathrm{I})$ & 0.21 \\
\hline
\end{tabular}

IInformation missing for four cases

2Information missing for one case

Significant $\mathrm{p}$-values are darkened.

with the risk of death $(\mathrm{p}=0.044)$. For other unfavourable treatment outcomes, significant risk factors were pause(s) in treatment, treatment group B and internal medicine being responsible at the end of the treatment (Table 4).

For death and other unfavourable outcomes together, significant risk factors in the multinomial logistic regression model were male sex $(\mathrm{p}=0.005)$, high age $(\mathrm{p}=0.03)$, pause $(s)$ in treatment $(\mathrm{p}<0.001)$, treatment group other than $A(p=0.003)$ and any other than a pulmonary specialty being responsible for ending the treatment ( $\mathrm{p}<$ $0.001)$. Earlier TB was a significant factor for favourable outcome $(\mathrm{p}=0.012)$.

When we analysed all 656 cases in the cohort with known outcome, including those 27 without treatment, the associations observed in univariate and multivariate analysis as significant were the same as with the 629 cases of the presented analysis.

\section{Discussion}

We analysed a large 2-year national cohort of cultureproven pulmonary tuberculosis cases for patient- and treatment-system related risk factors of unfavourable outcome. Apart from previously known patient-related risk factors for an unfavourable outcome, we observed a significant association with unfavourable outcome for the specialty responsible for treatment being other than pulmonary, but not for the volume of cases that the unit treated per year.
Due to the strictly controlled data collection process and high coverage, as reported previously [26], the data is highly representative. $\mathrm{TB}$ treatment recommendations and treatment organisation, as well as the proportion of foreign born, the age distribution and the case fatality rate have all remained unchanged since the study period in 1995-1996, making the analysis and conclusions valid for the present.

Due to relatively small number of deaths, the power of the study to investigate death as outcome was limited. The study was retrospective. Therefore, despite the meticulous conduct, it is possible that not all factors such as co-morbid conditions were recorded in the case notes.

Due to the fact that the TB patients in Finland are exceptionally old [13], contributing to the risk of death in several ways, we analysed separately the risk factors associated with death as outcome, as well as the risk factors for other unfavourable outcomes which may better reflect system features that may be amenable for improvement. Increasing age was strongly associated with death, contributing to the high case fatality ratio observed, and the major reason for not reaching the WHO targets for favourable outcomes. High age has been previously reported to be a risk factor for death, partly due to increasing comorbidities as well as the general physiological deterioration with age $[7,12,21,22]$, because of which close monitoring of treatment in older patients is necessary. In older population it is often difficult to determine 
Table 3: Univariate analysis of the association of treatment system - related characteristics with an unfavourable outcome in 629 cases treated for at least 24 hours

\begin{tabular}{|c|c|c|c|c|c|c|c|c|}
\hline \multirow[t]{2}{*}{ Variable } & & \multirow{2}{*}{$\begin{array}{c}\text { Total } \\
\mathrm{N}\end{array}$} & \multicolumn{3}{|c|}{ Death } & \multicolumn{3}{|c|}{ Other unfavourable } \\
\hline & & & $\mathrm{N}$ & OR $(95 \% \mathrm{Cl})$ & $P$ & $N$ & OR $(95 \% \mathrm{Cl})$ & $P$ \\
\hline \multirow[t]{4}{*}{ Specialty responsible for starting treatment ${ }^{1}$} & pulmonary & 579 & 90 & 1 & & 76 & I & \\
\hline & internal medicine & 34 & 11 & $2.52(1.17-5.45)$ & 0.018 & 3 & $0.82(0.24-2.81)$ & 0.75 \\
\hline & general medicine & 6 & 2 & $3.06(0.50-18.58)$ & 0.22 & 61 & I.8I (0.18-17.65) & 0.61 \\
\hline & other & 9 & 4 & $3.67(0.97-13.34)$ & 0.056 & 0 & - & - \\
\hline \multirow[t]{3}{*}{ Specialty responsible for ending treatment ${ }^{2}$} & pulmonary & 531 & 61 & 1 & & 67 & 1 & \\
\hline & general medicine & 47 & 22 & $6.92(3.59-13.34)$ & $<0.001$ & 4 & $1.15(0.38-3.44)$ & 0.81 \\
\hline & other & 15 & 6 & $4.96(1.66-14.77)$ & 0.004 & 1 & $0.75(0.093-6.11)$ & 0.79 \\
\hline \multirow[t]{2}{*}{ Change of specialty responsible for treatment ${ }^{2}$} & no & 530 & 66 & 1 & & 71 & 1 & \\
\hline & yes & 91 & 40 & $5.29(3.21-8.72)$ & $<0.001$ & 6 & $0.74(0.30-1.79)$ & 0.68 \\
\hline \multirow[t]{4}{*}{ Number of cases per year for unit giving initial treatment } & $1-4$ & 36 & 6 & $0.91(0.355-2.34)$ & 0.85 & 5 & $1.19(0.59-2.40)$ & 0.64 \\
\hline & $5-10$ & 30 & 46 & $1.20(0.46-3.16)$ & 0.71 & 5 & $0.67(0.32-1.43)$ & 0.30 \\
\hline & $11-29$ & 286 & 50 & $0.84(0.54-1.32)$ & 0.46 & 33 & $1.16(0.59-2.28)$ & 0.67 \\
\hline & $30-$ & 277 & 50 & 1 & & 37 & 1 & \\
\hline \multirow[t]{3}{*}{ Number of cases per year for unit responsible for ending treatment } & $1-4$ & 93 & 33 & $3.27(1.83-5.84)$ & $<0.001$ & 15 & $1.79(0.89-3.63)$ & 0.11 \\
\hline & $11-29$ & 278 & 35 & $0.74(0.44-1.23)$ & 0.24 & 31 & $0.79(0.46-1.36)$ & 0.39 \\
\hline & $30-$ & 220 & 35 & I & & 29 & 1 & \\
\hline \multirow[t]{6}{*}{ Treatment group } & standard treatment $\mathrm{A}$ & 309 & 64 & I & & 25 & 1 & \\
\hline & standard treatment $\mathrm{B}$ & 54 & 7 & $0.86(0.36-2.06)$ & 0.73 & 19 & $5.97(2.92-12.20)$ & $<0.001$ \\
\hline & standard treatment $\mathrm{C}$ & 33 & 1 & $0.13(0.018-0.99)$ & 0.05 & 6 & $2.03(0.76-5.41)$ & 0.16 \\
\hline & standard treatment $\mathrm{D}$ & 155 & 24 & $0.72(0.43-1.21)$ & 0.28 & 16 & $1.22(0.63-2.38)$ & 0.55 \\
\hline & other combination & 9 & 4 & $0.56(0.25-1.25)$ & 0.16 & 2 & $5.87(0.94-36.81)$ & 0.06 \\
\hline & ineffective & 69 & 8 & $4.58(1.00-21.01)$ & 0.05 & 12 & $2.16(1.01-4.58)$ & 0.05 \\
\hline \multirow[t]{2}{*}{ Treatment combination } & standard (A - D) & 548 & 97 & I & & 66 & 1 & \\
\hline & non-standard & 81 & 11 & $0.78(0.38-1.55)$ & 0.62 & 14 & $1.46(0.77-2.77)$ & 0.28 \\
\hline \multirow[t]{2}{*}{ Change in treatment group } & no & 433 & 91 & 1 & & 41 & 1 & \\
\hline & yes & 196 & 17 & $0.40(0.23-0.70)$ & 0.001 & 39 & $2.05(1.26-3.31)$ & 0.004 \\
\hline \multirow[t]{2}{*}{ Pause of treatment ${ }^{2}$} & no & 464 & 88 & I & & 37 & 1 & \\
\hline & yes & 157 & 16 & $0.64(0.36-1.13)$ & 0.14 & 42 & $3.97(2.42-6.562)$ & $<0.001$ \\
\hline \multirow[t]{2}{*}{ Pause during intensive phase ${ }^{2}$} & no & 483 & 91 & 1 & & 44 & 1 & \\
\hline & yes & 134 & 13 & $0.58(0.31-1.082)$ & 0.09 & 35 & $3.22(1.95-5.32)$ & $<0.001$ \\
\hline \multirow[t]{2}{*}{ Pause during intensive phase, due to side effect } & no & 523 & 97 & 1 & & 56 & 1 & \\
\hline & yes & 106 & 11 & $0.59(0.30-1.16)$ & 0.13 & 24 & $2.23(1.30-3.84)$ & 0.005 \\
\hline Pause during continuation phase & NA (other + ineffective) & 78 & & & & & & \\
\hline
\end{tabular}

Information missing for one case

2Information missing for $7-12$ cases

Significant p-values are darkened. 
Table 4: Multivariate analysis of 6 I I cases ( 18 were left out due to missing values) treated at least 24 hours, odds ratio for death or other unfavourable (transfer out, default, physician's decision to stop early) outcomes. Reference category is favourable treatment outcome

\begin{tabular}{|c|c|c|c|c|c|c|c|}
\hline \multirow[t]{2}{*}{ Variable } & & \multicolumn{3}{|c|}{ Death } & \multicolumn{3}{|c|}{ Other unfavourable } \\
\hline & & $\mathrm{N}$ & OR $(95 \% \mathrm{Cl})$ & $P$ & $N$ & OR $(95 \% \mathrm{Cl})$ & $P$ \\
\hline \multirow[t]{2}{*}{ Sex } & female & 34 & I & & 28 & 1 & \\
\hline & male & 68 & $2.51(1.42-4.45)$ & 0.002 & 48 & $\mathrm{I} .47(0.83-2.6 \mathrm{I})$ & 0.18 \\
\hline Age at diagnosis & risk per five years & 102 & $1.29(1.16-1.42)$ & $<0.001$ & 76 & $0.96(0.88-1.04 I)$ & 0.29 \\
\hline \multirow{2}{*}{ Immunosuppression } & no & 74 & I & & 72 & $\mathrm{I}$ & \\
\hline & yes & 28 & $2.11(1.12-3.97)$ & 0.020 & 4 & $0.32(0.097-1.062)$ & 0.063 \\
\hline \multirow[t]{2}{*}{ TB history } & no & 96 & 1 & & 73 & $\mathrm{I}$ & \\
\hline & yes & 6 & $0.36(0.133-0.97)$ & 0.044 & 3 & $0.32(0.087-1.16)$ & 0.082 \\
\hline \multirow[t]{4}{*}{ Specialty responsible for ending treatment } & pulmonary & 58 & 1 & & 67 & 1 & \\
\hline & internal medicine & 16 & $14.08(4.76-4 \mid .66)$ & $<0.00$ I & 4 & $6.89(1.66-28.59)$ & 0.008 \\
\hline & general medicine & 22 & $6.24(3.00-12.98)$ & $<0.001$ & 4 & $2.11(0.65-6.86)$ & 0.21 \\
\hline & other & 6 & $4.72(1.46-15.33)$ & 0.010 & 1 & $0.58(0.060-5.68)$ & 0.64 \\
\hline \multirow[t]{2}{*}{ Pause of treatment } & no & 86 & 1 & & 36 & 1 & \\
\hline & yes & 16 & $0.69(0.33-1.47)$ & 0.34 & 40 & $3.46(1.92-6.27)$ & $<0.001$ \\
\hline \multirow[t]{6}{*}{ Treatment group } & standard treatment A & 60 & 1 & & 23 & 1 & \\
\hline & standard treatment B & 7 & $0.85(0.30-2.42)$ & 0.76 & 19 & $5.92(2.6 \mathrm{I}-13.44)$ & $<0.001$ \\
\hline & standard treatment $\mathrm{C}$ & 1 & $0.146(0.017-1.22)$ & 0.076 & 6 & $1.41(0.48-4.12)$ & 0.53 \\
\hline & standard treatment D & 24 & $1.42(0.76-2.67)$ & 0.28 & 15 & $0.94(0.45-1.95)$ & 0.86 \\
\hline & other combination & 8 & $1.15(0.43-3.07)$ & 0.79 & 11 & $1.54(0.63-3.75)$ & 0.34 \\
\hline & ineffective & 2 & $2.64(0.29-24.38)$ & 0.39 & 2 & $3.54(0.49-25.30)$ & 0.21 \\
\hline
\end{tabular}

Significant $p$-values are darkened.

the causal relationship between tuberculosis and death Based on the findings of an earlier Finnish study, it is probable that about a third of the deaths in our study were not directly attributable to tuberculosis [33].

In our aging population of TB cases, in the absence of TB/ HIV co-infections, we found immunosuppression, virtually all due to other causes than HIV infection, from concomitant diseases and their medical treatment to be a risk factor for death, as has been previously reported $[7,14]$. For TB deaths in persons with diseases, which are themselves immunosuppressive and/or require immunosuppressive treatment, it is frequently difficult to explicitly determine the causal relationship between tuberculosis and death. As the clinical presentation of the underlying disease and TB may be difficult to differentiate, systematic use of rapid microbiological diagnosis and the early use of empiric treatment may be particularly valuable to improve outcome in this patient group.

In the analysis of treatment system -related factors, we found in univariate analysis significant or patterns of close to significant associations to death with specialty other than pulmonary beginning or ending the treatment, and with a switch in the specialty responsible for treatment. However, in multivariable analysis only the specialty service responsible for cessation of treatment being other than pulmonary was associated with death. Even though our data allowed controlling for a range of comorbid states, it is possible that in a patient population where half of the cases are older than 65 years, there could be more comorbidity in the group that ends up being treated in internal medicine and geriatric services.

An interesting finding in the univariate analysis for system-related risk factors was a reverse association of death with the number of cases treated per year by the unit in charge of ending the treatment. However, this association did not remain an independent predictor in multivariable analysis. For other unfavourable outcomes, there was no suggestion from univariate or multivariate analysis of an association with number of patient treated per year. While the volume of TB cases seen by each treating unit is becoming small, it is relevant to observe that favourable outcomes have been associated with increasing number of procedures for some other medical interventions such as treatment of leukaemia, AIDS and myocardial infarctions [23-25]. Pulmonary medicine in Finland treats the majority of tuberculosis cases, whether pulmonary or extra-pulmonary. The experience in the treatment of tuberculosis may therefore be greater in most pulmonary units than other specialty services. However, the volume of cases treated was used as a separate parameter in analysis. On the other hand, it is possible that the patient records do not fully cover all relevant comorbidities, which may be more common in other services than pulmonary. That in 
part can also explain association of death with the specialty service responsible for cessation of treatment being other than pulmonary. Overall, our results do not suggest that outcomes would improve by concentrating treatment in fewer clinical units in low incidence countries. This finding is relevant for low incidence countries with relatively little TB associated with immigration, homelessness, drug use and imprisonment, but may not be applicable in other settings.

Pause(s) in treatment were not found to be a risk factor for death. This can be due to deaths concentrating in the beginning of the treatment period in our study, leaving less possibility for pauses. On the other hand, pauses of treatment were a risk factor for other unfavourable outcome both in univariate analysis and in multivariate analysis. Pauses can be caused by side effects of treatment as well as non-compliance of a patient. There were more pauses in the initiation phase than in the continuation phase. Pauses during initiation may be more disadvantageous than in the later phase.

The potentially protective effect of history of earlier tuberculosis, although of borderline statistical significance, was an interesting finding. It seems likely that knowledge of tuberculosis in the past raises the early suspicion of the rare disease earlier, both in the patient as well as in treating doctor, leading to shorter delay in diagnostics and starting treatment, reported to affect outcome [34].

For unfavourable outcomes other than death, in univariate analysis association was found for being an immigrant, internal medicine service ending the treatment, belonging to treatment group B (commonly used when adverse effects necessitate switching of drugs or liver complications are anticipated), change in treatment group, and pauses in any stage of treatment. In multivariable analysis, however, only the system-related risk factors of internal medicine ending treatment, pause(s) and belonging to treatment group B remained independently associated with other unfavourable outcome. Earlier studies have found immigration as a significant risk factor $[7,12,16]$. For analysing immigration as a risk factor in our material, multinomial logistic regression model has a limited power, as the other unfavourable outcomes take place very early after start of treatment. Furthermore, the number of immigrants in this study is small, also limiting the power in multinomial model. No association between social risk factors and outcome was found, but that can depend on the dominance by unemployment rather than more extreme social issues which are rare in our country. In a recent analysis in London imprisonment, drug use and homelessness was found to be the most important predictors of poor outcome [35].

\section{Conclusion}

A high proportion of deaths as TB treatment outcome are typical in low-prevalence countries [7,9,12,15-18]. Our results suggest that outcomes would not improve by concentrating treatment in fewer units with more patients. Poor outcomes associated with immunosuppression and advanced age, with frequent comorbidity, stress a low threshold of suspicion, availability of rapid diagnostics, and early empiric treatment as possible approaches in attempting to improve treatment outcomes in countries with very low incidence of TB.

\section{Competing interests}

The author(s) declare that they have no competing interests.

\section{Authors' contributions}

TV checked the data, led the analysis and interpretation of the data, and prepared an initial draft of the manuscript. $\mathrm{PH}$ and JO performed the statistical analyses and contributed to drafting the manuscript. KL contributed to designing the study, analysis and interpretation of the data, and to drafting the manuscript. MK led the collection of data and critically revised the manuscript. PR conceived of and coordinated the project, contributed to analysis and interpretation of the data, to drafting the manuscript, and critically revised the manuscript. All authors read and approved the final manuscript.

\section{Acknowledgements}

This study was financially supported by the Finnish Anti-Tuberculosis Association Foundation. We thank Ms. Pirjo Turtiainen for technical assistance.

\section{References}

I. Clancy L, Rieder HL, Enarson DA, Spinaci S: Tuberculosis elimination in the countries of Europe and other industrialized countries. Eur Respir J 199I, 4:I288-I 295.

2. World Health Organization: WHO Tuberculosis Programme: framework for effective tuberculosis control. In World Health Organization Document WHO/TB/94.I 79 World Health Organization, Geneva; 1994.

3. Broekmans JF, Migliori GB, Rieder HL, Lees J, Ruutu P, Loddenkemper $\mathrm{R}$, Raviglione MC, World Health Organization, International Union Against Tuberculosis and Lung Disease, and Royal Netherlands Tuberculosis Association Working Group: European framework for tuberculosis control and elimination in countries with a low incidence. Recommendations of the World Health Organization (WHO), International Union Against Tuberculosis and Lung Disease (IUATLD) and Royal Netherlands Tuberculosis Association (KNCV) Working Group. Eur Respir J 2002, I 9(4):765-775.

4. Veen J, Raviglione M, Rieder HL, Migliori GB, Graf P, Grzemska M, Zalesky R: Standardized tuberculosis treatment outcome monitoring in Europe. Recommendations of a Working group of the World Health organisation (WHO) and the European Region of the International Union against Tuberculosis and Lung Disease (IUATLD) for uniform reporting by cohort analysis of treatment outcome in tuberculosis patients. Eur Respir J 1998, I 2:505-510.

5. WHO, IUATLD, and KNCV: Revised international definitions in tuberculosis control. Int J Tuberc Lung Dis 200I, 5(3):213-2I5.

6. EuroTB: Classification of treatment outcomes. WHO Euro/ EuroTB joint data collection - CISID 200I. 
7. Zellweger JP, Coulon P: Outcome of patients treated for tuberculosis in Vaud County, Switzerland. Int J Tuberc Lung Dis 1998, 2(5):372-377.

8. Wobeser W, Yuan L, Naus M, the Tuberculosis Treatment Completion Study Group: Outcome of pulmonary tuberculosis treatment in the tertiary care setting -Toronto 1992/93. Volume 160. Issue $6 \mathrm{CMA}$ : Canadian Medical Association Journal; 1999:789-794.

9. Chin DP, Cummings KC, Sciortino S, Snyder DC, Johnson LF, Westenhouse JL, Royce SE: Progress and problems in achieving the United States national target for completion of antituberculosis treatment. Int J Tuberc Lung Dis 2000, 4(8):744-75I.

10. Centis R, lanni A, Migliori GB: Evaluation of tuberculosis treatment results in Italy, report 1998. Tuberculosis section of the National AIPO Study Group on Infectious Disease and the SMIRA Group. Monaldi Arch Chest Dis 2000, 55(4):293-298.

II. Ormerod LP, Horsfield N, Green RM: Tuberculosis treatment outcome monitoring: Blackburn 1988-2000. Int J Tuberc Lung Dis 2002, 6(8):662-665.

12. Cayla JA, Caminero JA, Rey R, Lara N, Valles X, Galdos-Tanguis H, Working Group on Completion of Tuberculosis Treatment in Spain: Current status of treatment completion and fatality among tuberculosis patients in Spain. Int J Tuberc Lung Di 2004 8(4):458-464.

13. EuroTB and the national coordinators for tuberculosis surveillance in the WHO European Region: Surveillance of tuberculosis in Europe. Report on tuberculosis cases notified in 2004. Institut de veille sanitaire, Saint-Maurice, France 2006

14. Lillebaek T, Poulsen S, Kok-Jensen A: Tuberculosis treatment in Denmark: treatment outcome for all Danish patients in 1992. Int J Tuberc Lung Dis 1999, 3(7):603-6I2.

15. Trnka L, Daòkova $D$, Krejbich F: Is quarterly cohort analysis useful for assessing treatment outcomes in a low incidence country? Int J Tuberc Lung Dis 200I, 5(3):250-256

16. Helbling P, Medinger C, Altpeter E, Raeber PA, Beeli D, Zellweger JP: Outcome of treatment of pulmonary tuberculosis in Switzerland in 1996. Swiss Med Wkly 2002, I32(35-36):517-522.

17. Ormerod LP, Prescott RJ: The management of pulmonary and lymph node tuberculosis notified in England and Wales in 1998. Clin Med 2003, 3(I):57-6I.

18. Faustini A, Hall AJ, Perucci CA: Tuberculosis treatment outcomes in Europe: a systematic review. Eur Respir J 2005, 26:503-510

19. Grzybowski S, Enarson DA: The fate of cases of pulmonary tuberculosis under various treatment programmes. Bull Int Union Tuberc 1978, 53:70-75.

20. Vasankari T, Kokki M, Holmström P, Liippo K, Sarna S, Ruutu P: Great diversity of tuberculosis treatment in Finland. Euro Surveill 2007, I 2(I):. [Epub ahead of print]: PMID: I7370977

21. Farah M, Tverdall A, Steen T, Heldall E, Brantsaeter A, Bjune G: Treatment outcome of new culture positive pulmonary tuberculosis in Norway. BMC Public Health 2005, 5: 14.

22. Falzon D, Le Strat $Y$, Belghiti F, Infuso A, EuroTB Correspondents: Exploring the determinants of treatment success for tuberculosis cases in Europe. Int J Tuberc Lung Dis 2005, 9:1224-1229.

23. The Finnish Leukaemia Group: Interhospital differences in the treatment of acute leukaemia in adults. Scand J Haematol 1979 , 23:119-123.

24. Halm EA, Lee C, Chassin MR: Is volume related to outcome in health care? A systematic review and methodological critique of the literature. Ann Intern Med 2002, I 37:5 I I-520.

25. Thiemann DR, Coresh J, Oetgen WJ, Powe NR: The association between hospital volume and survival after acute myocardial infarction in elderly patients. N Engl J Med 1999, 340:1640-1648.

26. Kokki M, Holmström P, Ruutu P: High sensivity for tuberculosis in a laboratory-based national integrated infectious disease surveillance system in Finland. Euro Surveill 2005, 10:90-93.

27. Lääkintöhallitus: Tuberkuloosi ja sen lääkehoito. Finnish National Board of Health. Tuberculosis and its treatment. Kapseli 15. Lääkintöhallituksen julkaisu 1985. (in Finnish)

28. World Health Organization Tuberculosis Unit, Division of Communicable Disease: Guidelines for tuberculosis treatment in adults and children in National Tuberculosis Programmes. . WHO/ TB/9I, |61
29. American Thoracic Society: Treatment of tuberculosis and tuberculosis infection in adults and children. Am Rev Resp Dis 1986, 134:355-363.

30. Joint Tuberculosis Committee of the British Thoracic Society: Chemotherapy and management of tuberculosis in the United Kingdom: recommendations. Thorax 1990, 45:403-408.

31. Davies PDO: Clinical tuberculosis. London, MacMillan Education 1994.

32. Tala E: Tuberkuloosin lääkehoito ja -profylaksia. Tuberculosis treatment and prophylaxis. Duodecim 1993, 109:69-75. (in Finnish)

33. Vasankari T: Analysis of tuberculosis deaths in Finland from 1974 to 1993. Thesis. Turku University Series D 1998:304.

34. de Meer G, van Geuns HA: Rising case fatality of bacteriologically proven pulmonary tuberculosis in the Netherlands. Tuberc Lung Dis 1992, 73:83-86.

35. Story A, Murad S, Verheyen M, Roberts W, Hayward AC: Tuberculosis in London -the importance of homelessness, problem drug use and prison. Thorax 2007, 62(8):667-7I.

\section{Pre-publication history}

The pre-publication history for this paper can be accessed here:

\section{http://www.biomedcentral.com/1471-2458/7/291/pre} pub
Publish with Biomed Central and every scientist can read your work free of charge

"BioMed Central will be the most significant development for disseminating the results of biomedical research in our lifetime. "

Sir Paul Nurse, Cancer Research UK

Your research papers will be:

- available free of charge to the entire biomedical community

- peer reviewed and published immediately upon acceptance

- cited in PubMed and archived on PubMed Central

- yours - you keep the copyright

Submit your manuscript here:

http://www.biomedcentral.com/info/publishing_adv.asp
BioMedcentral 